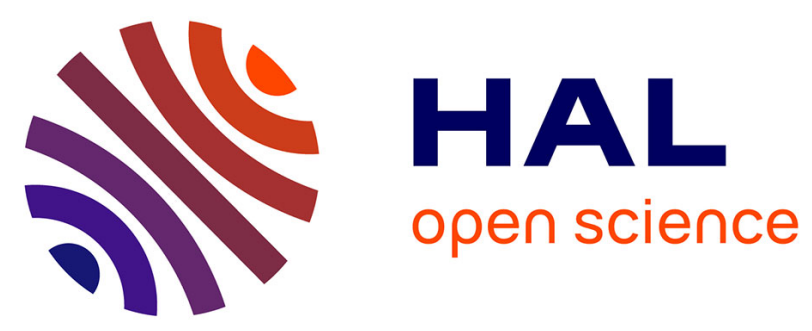

\title{
Long-term Efficacy of Interferon-Free Antiviral Treatment Regimens in Patients With Hepatitis C Virus-Associated Cryoglobulinemia Vasculitis
}

Patrice Cacoub, Si Nafa Si Ahmed, Yasmina Ferfar, Stanislas Pol, Dominique Thabut, Christophe Hézode, Laurent Alric, Cloe Comarmond, Gafaar Ragab, Luca Quartuccio, et al.

\section{To cite this version:}

Patrice Cacoub, Si Nafa Si Ahmed, Yasmina Ferfar, Stanislas Pol, Dominique Thabut, et al.. Long-term Efficacy of Interferon-Free Antiviral Treatment Regimens in Patients With Hepatitis C Virus-Associated Cryoglobulinemia Vasculitis. Clinical Gastroenterology and Hepatology, In press, 10.1016/j.cgh.2018.05.021 . hal-01826498

\section{HAL Id: hal-01826498 \\ https://hal.sorbonne-universite.fr/hal-01826498}

Submitted on 29 Jun 2018

HAL is a multi-disciplinary open access archive for the deposit and dissemination of scientific research documents, whether they are published or not. The documents may come from teaching and research institutions in France or abroad, or from public or private research centers.
L'archive ouverte pluridisciplinaire HAL, est destinée au dépôt et à la diffusion de documents scientifiques de niveau recherche, publiés ou non, émanant des établissements d'enseignement et de recherche français ou étrangers, des laboratoires publics ou privés. 
Manuscript Number: GASTRO 18-00404

Title: Long-term Efficacy of Interferon-Free Antiviral Treatment Regimens in Patients With Hepatitis C Virus-Associated Cryoglobulinemia Vasculitis

Short title: Interferon-Free Antivirals for HCV Cryoglobulinemia Vasculitis

Patrice Cacoub ${ }^{1,2,3,4}$, Si Nafa Si Ahmed ${ }^{5}$, Yasmina Ferfar ${ }^{1,2,3,4}$, Stanislas Pol ${ }^{6}$, Dominique Thabut ${ }^{7}$, Christophe Hezode ${ }^{8}$, Laurent Alric ${ }^{9}$, Cloe Comarmond ${ }^{1,2,3,4}$, Gafaar Ragab $^{10}$, Luca Quartuccioo ${ }^{11}$, Mohamed Hegazy ${ }^{10}$, Thierry Poynard ${ }^{7}$, Matthieu Resche Rigon ${ }^{12}$, David Saadoun ${ }^{1,2,3,4}$

${ }^{1}$ Sorbonne Universités, UPMC Univ Paris 06, UMR 7211, and Inflammation-ImmunopathologyBiotherapy Department (DHU i2B), F-75005, Paris, France; ${ }^{2}$ INSERM, UMR_S 959, F-75013, Paris, France; ${ }^{3}$ CNRS, FRE3632, F-75005, Paris, France; ${ }^{4}$ AP-HP, Groupe Hospitalier PitiéSalpêtrière, Department of Internal Medicine and Clinical Immunology, F-75013, Paris, France; ${ }^{5}$ Department of Hepatology, Hôpital Orléans, Orléans; ${ }^{6}$ Université Paris Descartes; APHP, Unité d’Hépatologie, Hôpital Cochin; ${ }^{7}$ Department of Hepatology, AP-HP, Groupe Hospitalier Pitié-Salpétrière, Paris; ${ }^{8}$ Department of Hepatology, APHP, Hôpital Henri Mondor, Créteil; ${ }^{9}$ Department of Internal Medicine and Digestive Diseases, CHU Purpan, UMR 152 Pharma Dev, IRD Toulouse 3 University, France ${ }^{10}$ Internal Medicine Department, Rheumatology and Clinical Immunology Unit, Faculty of Medicine, Cairo University, Egypt; ${ }^{11}$ University Hospital "Santa Maria della Misericordia", Udine, Italy; ${ }^{12}$ Department of Biostatistics and Medical Data Processing; INSERM U717, Hôpital Saint-Louis, Paris, France. 
Correspondence should be addressed to: Patrice Cacoub, AP-HP, Hôpital La Pitié-Salpêtrière, Department of Internal Medicine and Clinical Immunology, 83 boulevard de l'Hôpital. F-75013, Paris, France

Phone: + (33)(1) 421780 09. Fax: + (33)(1) 42178033.

E-mail: patrice.cacoub@aphp.fr

\section{Conflict of interest}

Patrice Cacoub has received consulting and lecturing fees from Abbvie, Astra Zeneca, BristolMyers Squibb, Gilead, Glaxo Smith Kline, Janssen, Merck Sharp Dohme, Roche, Servier and Vifor. Si Nafa Si Ahmed has received consulting and lecturing fees from Abbvie, Bristol Myers Squibb, Gilead, Janssen and Roche. Laurent Alric has received consulting and lecturing fees from or was investigator for Gilead, Bristol Myers Squibb, Janssen, Abbvie, Merck Sharp Dhome. Christophe Hézode has been an adviser and speaker for Abbvie, Bristol Myers Squibb, Gilead, Janssen, and Merck Sharp Dohme. Stanislas Pol has been a speaker for Glaxo Smith Kline, Bristol Myers Squibb, Boehringer Ingelheim, Janssen, Gilead, Roche, Merck Sharp Dohme, Sanofi, Novartis, Vertex, and Abbvie; has received grants from Bristol Myers Squibb, Gilead, Roche, and Merck Sharp Dohme; and has been a board member for Glaxo Smith Kline, Bristol Myers Squibb, Boehringer Ingelheim, Janssen, Gilead, Roche, Merck Sharp Dohme, Sanofi, Novartis, Vertex, and Abbvie. Thierry Poynard is the founder of BioPredictive, which markets FibroTest (patent belong to Public Organization APHP). David Saadoun has received consulting and lecturing fees from Medimmune, Abbvie, Bristol Meyer Squibb, Roche, Servier, Gilead, AstraZeneca and Glaxo Smith Kline.

All other authors have nothing to disclose.

\section{Contributorship}

- Study concept and design: DS, PC

- Acquisition of data: DS, SP, YF, ASB, LA, CH, SNSA, CC, LDSM, LM, TP, PC 
- Analysis and interpretation of data: DS, MRR, PC

- Drafting of the manuscript: DS, MRR, PC

- Critical revision of the manuscript for important intellectual content: DS, SP, YF, ASB, LA, CH, SNSA, LDSM, LM, TP, MRR, PC

Word count: 3400 words

This article includes 3 Tables and 1 figure.

\author{
Abbreviations \\ HCV, hepatitis C virus \\ CryoVas, cryoglobulinemia vasculitis \\ DAA, direct antiviral agents \\ IFN, interferon alpha \\ SOF, sofosbuvir \\ SVR, sustained virological response \\ OR, Odds Ratio \\ CI, confidence interval
}

\title{
Sources of Funding
}

None. 


\begin{abstract}
:
Background \& Aims: In small-size and short-term studies of hepatitis C virus-associated cryoglobulinemia vasculitis (HCV-CryoVas), patients had a higher rate of response and tolerance to direct-acting antiviral (DAA) agents than interferon-containing regimens. We collected follow-up data from a clinical trial to determine the long-term effectiveness and tolerance of all-oral, interferon-free DAA regimens in patients with CryoVas.
\end{abstract}

Methods: We collected follow-up data from a prospective international multi-center cohort study of 148 patients with symptomatic HCV-CryoVas (53.7\% with cirrhosis and $49.3 \%$ naïve to treatment with DAAs). All patients received DAA (sofosbuvir plus daclatasvir, $n=53$; sofosbuvir plus ribavirin, $\mathrm{n}=51$; sofosbuvir plus ledipasvir, $\mathrm{n}=23$; or sofosbuvir plus simeprevir, $\mathrm{n}=18$ ), for 12 or 24 weeks, from 2014 through 2017; the median follow-up time was 15.3 months. A complete clinical response was defined as improvement of all organs involved at baseline and the absence of clinical relapse; a partial response was defined as improvement in some but not all organs involved at baseline. The primary endpoint was clinical response of CryoVas symptoms at week 12 after stopping DAA therapy.

Results: A complete response was reported for 106 patients (72.6\%), a partial response for 33 patients (22.6\%), and no response for 7 patients (4.8\%). Cryoglobulins were no longer detected in blood samples from $53.1 \%$ of patients and $97.2 \%$ of the patients had a sustained virologic response to therapy. Premature DAA withdrawal was reported for $4.1 \%$ of patients. Factors associated with no or partial response to therapy included a severe form of CryoVas (odds ratio, 0.33, 95\% CI, 0.12-0.91; $P=.03$ ) and peripheral neuropathy (odds ratio, 0.31; 95\% CI 0.11-0.84; $P=.02$ ). After a median followup time of 15.3 months, 4 patients (2.8\%) died. The CryoVas manifestation of purpura was cleared from $97.2 \%$ of patients, renal involvement from $91.5 \%$ of patients, arthralgia from $85.7 \%$ of patients, neuropathy from $77.1 \%$ of patients, and cryoglobulinemia from $52.2 \%$.

Conclusions: In a long-term follow-up analysis of data from a clinical trial, we found that more than 95\% of patients with HCV-CryoVas have a full or partial response of symptoms to different DAA 
treatment regimens. Fewer than 5\% of patients stop therapy prematurely and less than 3\% die. A severe form of CryoVas and peripheral neuropathy were associated with lack of response of HCVCryoVas to DAA therapy.

KEY WORDS: DAA; VASCUVALDIC 3 study; risk; prognostic factor 


\section{Introduction}

Symptomatic cryoglobulinemia vasculitis (CryoVas), an immune complex-mediated systemic vasculitis that mainly affects small- and medium-sized vessels, has been observed in about $15 \%$ of hepatitis C virus (HCV)-infected patients (1-6). HCV-associated CryoVas (HCV-CryoVas) is a severe disease with an estimated 5-year mortality rate of 25\% (1,3,7). Besides liver fibrosis, the prognosis of HCV-CryoVas is mainly dependent on vasculitis involvement of the kidney, central nervous system, heart and digestive tract (7-12).

Major advances in the treatment of HCV-CryoVas have been achieved over the last decade (13-18). Two prospective randomized controlled trials have demonstrated the superiority of rituximab monotherapy in comparison with conventional immunosuppressive therapy in patients with HCVCryoVas that is refractory to antiviral therapy $(16,17)$. However, in the absence of HCV clearance, frequent relapses occurred when B cells reemerged in the peripheral blood.

Achievement of a sustained virological response (SVR) remains the main goal in HCVCryoVas patients since clinical remission of vasculitis is closely associated with viral clearance (20). Interferon alpha (IFN)-based treatment has shown a certain efficacy, although tolerance was poor (8, 20-22). The recent development of direct-acting antiviral (DAA) agents with increased antiviral potency has benefited HCV-CryoVas patients. The first use of DAA (Peg-IFN/ribavirin plus boceprevir or telaprevir) in HCV-CryoVas patients resulted in a complete clinical response in 56.5\% of cases $(23,24)$. However, grade 3 or 4 adverse events were observed in up to $43.5 \%$, and antiviral therapy discontinuation was required in one-third. More recently, all oral IFN-free DAA regimens (21, 22) have shown good efficacy and tolerance profile in small series of HCV-CryoVas patients. In the VASCUVALDIC 1 prospective study (25), 87.5\% of twenty-four patients reported a complete response of CryoVas manifestations, 74\% had an SVR 12 weeks post-treatment (SVR12) and 8\% experienced serious adverse events. In a retrospective case series of 12 HCV-CryoVas patients, an SVR12 was achieved in 83\% of patients, and 17\% experienced serious adverse events (26). Sofosbuvir-based IFN-free DAA therapy was given to a cohort of 44 Italian HCV-CryoVas patients, who all showed both an SVR post-treatment and a CryoVas clinical response (27). In a Spanish study, 
71\% of 35 HCV-CryoVas patients achieved a complete clinical response and 94\% had an SVR12 after DAA treatment (28). Finally, in the VASCUVALDIC 2 study, a complete clinical response was reported in $90.2 \%$ of $41 \mathrm{HCV}$-CryoVas patients and an SVR12 in all (29).

There are still unresolved issues in this field. Considering the very high virological and clinical response rates after the use of IFN-free DAAs, the question remains as to which HCVCryoVas patients would still need additional immunosuppressive drugs. Also, the long-term efficacy on CryoVas manifestations and cryoglobulin production after DAA treatment remains to be seen. Based on a large prospective cohort of HCV-CryoVas patients treated with DAA who had long-term follow-up, we aimed to 1) evaluate the effectiveness and tolerance of different IFN-free DAA combinations, and 2) search for predictive factors of complete remission of vasculitis manifestations. 


\section{Patients and Methods}

\section{Patients}

The VASCUVALDIC 3 study is an international open-label, prospective, multicenter study including consecutive patients with active HCV-CryoVas who were recruited between 2014 and 2017. Patient eligibility included a minimum age of 18 years, informed consent, the presence of active HCV-vasculitis defined by skin, joint, renal, peripheral nerve, central neurological, digestive, pulmonary and/or cardiac involvement, and chronic active HCV infection (positive HCV RNA). Exclusion criteria included non-active CryoVas, human immunodeficiency virus or active hepatitis B virus infection, and current decompensated cirrhosis. Patients with a severe form of vasculitis were defined by skin necrosis, glomerulonephritis, and heart, gut and/or central nervous system involvement.

The baseline clinical evaluation included recent weight loss, neurologic involvement (peripheral and/or central nervous system), cutaneous involvement (purpura, skin necrosis), arthralgia, gastrointestinal tract involvement, renal involvement (proteinuria, hematuria and glomerular filtration rate [GFR]), and clinical signs of hepatic involvement. All patients had follow-up visits every 4 weeks until week 36, and at the end of follow-up. The diagnosis of nonHodgkin's lymphoma was based on the World Health Organization (WHO) criteria (30). The study was performed according to the Declaration of Helsinki and was approved by the ethics committee of Pitié-Salpêtrière Hospital (Paris, France).

\section{Immunologic and virological markers}

HCV viral load was quantified using the Abbott RealTime HCV assay (Abbott, Rungis, France). HCV genotyping was performed by NS5b gene sequencing (31). Laboratory evaluation included a complete blood count, serum chemistry profile, alanine aminotransferase (ALT), rheumatoid factor activity, C4 fraction of complement and cryoglobulin. Cryoglobulins were measured as previously described (32) and were classified according to the method described by 
Brouet et al. (33). The estimation of glomerular filtration rate (GFR) was determined by modification of diet in renal disease (MDRD) study equations. Urine collection was performed to quantify protein excretion. Liver fibrosis was evaluated (by liver biopsy and/or non-invasive tests) according to the previously validated Metavir scoring system (34).

\section{Study Design}

All patients with active HCV-CryoVas who met the inclusion criteria during the study period were prospectively included. All patients received antiviral therapy with sofosbuvir-based IFN-free DAA for 12 or 24 weeks (the duration was at the investigators' discretion). All antiviral combinations were ribavirin-free except for the sofosbuvir plus ribavirin group. Use of nonantiviral treatment, i.e. corticosteroids, immunosuppressants or plasma exchange, was at the investigators' discretion.

\section{Endpoints}

The primary endpoint was a complete clinical response of CryoVas at week 12 post-DAA treatment. A complete clinical response was defined as improvement of all organs involved at baseline and the absence of clinical relapse. Skin and joint improvement were evaluated clinically. Renal improvement was evaluated biologically, i.e. proteinuria $<0.3 \mathrm{~g} / 24 \mathrm{~h}$, resolution of haematuria and improvement of GFR $>20 \%$ at week 24 (if GFR $<60 \mathrm{ml} / \mathrm{min} / 1.73 \mathrm{~m}^{2}$ at diagnosis). Peripheral neurological improvement was evaluated clinically (visual analogue scales, muscle testing) and/or electrophysiologically (electromyogram abnormalities at week 12 postDAAs compared with baseline). Patients defined as partial clinical responders at week 12 postDAAs had improvement in some but not all organs involved at baseline. Patients with no clinical improvement at week 12 post-DAAs were defined as treatment failure.

The secondary endpoints included 1) a SVR at week 12 post-DAAs (SVR12), 2) the rate and type of side effects during the DAA treatment period and the follow-up, and 3) clinical response rates of CryoVas symptoms at the end of follow-up. A SVR was defined as the absence of detectable serum HCV RNA 12 weeks after the end of antiviral therapy. The remaining patients were classified as virological failures. 


\section{Safety assessments}

Data on all adverse events were collected prospectively during the follow-up.

\section{Statistical analysis}

Quantitative variables are reported as medians and ranges. They were compared by the Wilcoxon Rank-Sum test to assess differences between responders and non-responders or by the Kruskal-Wallis test to assess differences among treatment groups. Categorical variables were described by counts and percentages and were compared between groups using the Fisher's exact test. Treatment effects were evaluated using logistic models and tested using partial Wald tests. Odds ratios (OR) with their 95\% confidence intervals (95\% CI) are given. Survival was estimated using the Kaplan-Meier method. Analyses of effectiveness and tolerability were performed on the intention-to-treat population, which was defined as all enrolled patients who received at least one dose of DAA. All tests were 2-sided; P-values less than 0.05 were considered significant. Analyses were performed using R statistical package, version 3.3.1 (www.r-project.org).

All co-authors had access to the study data and had reviewed and approved the final manuscript. 


\section{Results}

\section{Baseline characteristics of HCV-CryoVas patients}

One hundred and forty-eight HCV-CryoVas patients, with a median (IQR) age of 57 (51; 67) years, were included (Table 1). The main clinical features of CryoVas at baseline included arthralgia (64.4\%), neuropathy (58.1\%), purpura (57.4\%), glomerulonephritis (16.9\%), skin necrosis (10.1\%), and other visceral involvement (6.1\%). A severe form of CryoVas was noted in 43 (29.1\%) patients. B-cell lymphoma was present in 13 (8.8\%) patients. The mean cryoglobulin level was 168 (50; 447) mg/L. Seventy-one percent of patients had type II mixed cryoglobulinemia. A low C4 serum level was noted in 70.1\%. Seventy patients (53.7\%) had Child-Pugh class A cirrhosis. Seventy-three (49.3\%) patients were antiviral treatment-naïve, whereas seventy-five (50.7\%) were virological non-responders to previous IFN-based antiviral therapy. Previous immunosuppressive treatments had been given to $21.3 \%$ of patients, i.e. corticosteroids (18.4\%), plasma exchange (3.7\%) and rituximab (2.2\%).

\section{Treatment efficacy and predictive factors of complete remission of vasculitis}

Antiviral therapy included sofosbuvir (SOF) plus daclatasvir ( $\mathrm{n}=53$ ), SOF plus ribavirin $(n=51)$, SOF plus ledipasvir ( $n=23)$, and SOF plus simeprevir $(n=18)$ (Table 2). Twelve weeks following DAA discontinuation, 106 (72.6\%) patients showed a complete clinical response, 33 (22.6\%) a partial response and 7 (4.8\%) had no response of their CryoVas manifestations. Partial responses were based on persistent renal insufficiency (n=17) and/or peripheral neuropathy $(n=29)$. Non response was related to kidney involvement $(n=3)$, peripheral neuropathy $(n=2)$, and skin necrosis ( $n=2)$. Fifty-three percent of cases showed resolution of cryoglobulins. An SVR12 was obtained in 141/145 (97.2\%) patients. The non-SVR12 patients were complete $(n=3)$ or partial $(\mathrm{n}=1)$ responders, although three still had a detectable cryoglobulinemia. Among patients with B-cell lymphoma, 10 patients showed a complete clinical response, 2 partial response and 1 no response of CryoVas manifestations while a cryoglobulinemia was detectable in 10. During antiviral therapy, $14.3 \%$ of patients received corticosteroids, immunosuppressant or plasma exchange. 
The differences in the baseline characteristics between patients who showed a complete response ( $n=106)$ versus those who had a partial or no response $(n=40)$ of the CryoVas manifestations were the presence of neuropathy (54.3\% vs. $73.3 \%)$, renal involvement (12.2\% vs. $30 \%$ ), arterial hypertension ( $25 \%$ vs. $46.7 \%$ ), a severe form of CryoVas (26\% vs. $35 \%$ ), and previous use of immunosuppressants and/or plasma exchange (17.6\% vs. 34.6\%). After multivariate analysis, two baseline factors remained independently associated with a poor response of CryoVas manifestations: a severe form of CryoVas [OR 0.33, 95\% CI 0.12-0.91; $\mathrm{P}=0.03$ ] and peripheral neuropathy [OR 0.31, 95\% CI 0.11-0.84; $\mathrm{P}=0.02$ ].

\section{Comparison of different DAA combinations for tolerance and efficacy}

There was a more frequent rate of HCV genotype 3, 5 or 6 in the SOF plus daclatasvir group (Table 3). Patients in the SOF plus simeprevir group had been treated with Rituximab more frequently. Premature DAA withdrawal due to side effects was noted in 6 (4.1\%) patients. Anemia was the most frequent side effect in $29 \%$ and $19 \%$ of the SOF plus ribavirin and SOF plus simeprevir groups, respectively. Skin manifestations were found in $8 \%$ and $12 \%$ of the SOF plus simeprevir and SOF plus ribavirin groups, respectively. Nausea was reported in $6 \%$ and $2 \%$ of the SOF plus simeprevir and SOF plus daclatasvir groups, respectively.

The rates of complete remission of CryoVas manifestations at week 12 post-DAA treatment and at the end of follow-up were $62 \%$ and $70 \%$ for SOF plus ribavirin, $67 \%$ and $72 \%$ for SOF plus simeprevir, $79 \%$ and $88 \%$ for SOF plus daclatasvir, and $87 \%$ and $87 \%$ for SOF plus ledipasvir, respectively. Using the SOF plus ribavirin combination as a reference group (because of its lowest CryoVas response rate), only the SOF plus ledipasvir combination showed significant superiority [OR 4.09, 95\% CI 1.19-19.00; $\mathrm{P}=0.04$ ], while there was a superiority trend for the SOF plus daclatasvir combination [OR 2.28, 95\% CI 0.96-5.63; P=0.06] (Figure 1). The results were similar when the model was adjusted for the severity of vasculitis, type III mixed cryoglobulinemia and B-cell lymphoma ( $\mathrm{p}=0.03$ and $\mathrm{p}=0.09$ for SOF plus ledipasvir and SOF plus daclatasvir, respectively).

After a median follow-up of 15.3 months, 4 (2.8\%) patients had died and no CryoVas 
relapse was observed. The causes of death were hepatocellular carcinoma (two patients: one partial responder and one complete responder), alveolar pulmonary hemorrhage (one complete responder), and acute respiratory failure (one complete responder). The 12-month survival rate was 97\% [95\% CI 94, 100]. The rates of CryoVas manifestation clearance at the end of follow-up were as follows: purpura (97.2\%), renal involvement (91.5\%), arthralgia (85.7\%), neuropathy (77.1\%) and cryoglobulinemia (52.2\%). 


\section{Discussion}

Up to recent period, HCV-CryoVas had been a severe condition with a 10-year mortality of up to $40 \%$ (3) and an overall risk of non-Hodgkin's lymphoma that was 30 times higher than the general population (35). The most striking results found by the present study, using different DAA combinations in a large cohort of HCV-CryoVas patients with long-term follow-up, are 1) a high rate (95.2\%) of improvement in CryoVas manifestations at week 12 post-DAA treatment; 2) a low mortality rate (2.8\%), with a 12-month survival rate of 97\%; and 3) two baseline factors predictive of a poor response of CryoVas manifestations, i.e. a severe form of vasculitis and peripheral neuropathy.

The therapeutic approach for HCV-CryoVas has dramatically changed with all oral INFfree therapies. In published series (25-29), the number of HCV-CryoVas patients varied from 10 to 44, and the follow-up period was less than six months after stopping DAA. The studies reported SVR rates from $74 \%$ to $100 \%$, and complete response rates of CryoVas manifestations from $83 \%$ to100\%. Such very high rates of CryoVas remission were confirmed in the present study (95.2\%). However, CryoVas patients who presented with a severe form of vasculitis or peripheral neuropathy were 3-times less likely to obtain a complete clinical response. These results are likely to be clinically useful for identifying which patients would still need additional immunosuppressive drugs. For patients with a severe form of life-threatening CryoVas, additive treatments, such as rituximab and/or plasmapheresis, should be rapidly introduced. Immunosuppressants are not mandatory for those who present with peripheral neuropathy since there are no associated life-threatening risks, and it would take more time to achieve a complete response of the neurological manifestations. Of note, permanent damage may be irreversible such as peripheral neuropathy or renal failure, making them insensitive to treatments.

In the DAA era, greater antiviral efficacy and better tolerance of antivirals in HCVCryoVas patients has been associated with less frequent use of non-antiviral treatments, i.e. corticosteroids, immunosuppressants or plasma exchange (14.3\% in the present study). Data from 
the French group clearly showed a decreased rate of use of non-antiviral treatments, from the PegIFN-ribavirin era (43\%) to the SOF plus daclatasvir era $(4.8 \%)(20,23,29)$, which is similar to the 4.5\% rate reported by Gragnani et al. (27). This was also found in a recent study where the corticosteroid doses had been reduced or treatment withdrawn in 10 out of 13 patients (28). Overall, these results probably reflect the greater antiviral efficacy of more recent combinations. HCV-CryoVas has long been a severe and challenging condition with respective estimated 5- and 10 -year mortality rates of $25 \%$ and $40 \%(3,8)$. By using IFN-free DAA the mortality rates of patients with HCV-CryoVas have decreased dramatically, being less than 3\% in the present study.

Use of DAA in HCV-CryoVas patients has been associated with adverse event rates of 49\%-67\% when ribavirin was included. When SOF plus daclatasvir was given without ribavirin, the adverse event rate was only $17 \%$ (29). In the present analysis, anemia and the use of erythropoietin were seen mainly in the SOF plus ribavirin group, and to a lesser extent in the SOF plus simeprevir group. Premature DAA withdrawal due to side effects was noted in only $4.1 \%$. It has been recently reported that the combination of SOF plus daclatasvir is able to correct most immune abnormalities found in HCV-CryoVas patients, such as T regulatory cell deficiency and expansion of $\operatorname{IgM}^{+} \mathrm{CD} 21^{- \text {llow }}$ memory B, T follicular helper and Th17 cells (36). However, despite very good virological and clinical results, all studies using DAA in HCVCryoVas patients reported a significant proportion of patients that were still positive for cryoglobulins (50-61\%), as was also found in $46.9 \%$ of the present long-term study (25-29). Case reports of HCV-CryoVas relapse have been described either as the reappearance or increase of cryoglobulin levels despite SVR following INF-free therapy $(37,38)$. This suggests that some patients continue to have B-lymphocyte clonal expansion after SVR (39, 40). Therefore, patients with persistently positive serum cryoglobulin results will need special attention and follow-up, particularly as they appear to be at very high risk of developing malignant lymphoproliferative disorders $(41,42)$.

This study has some limitations, with one being that it was an open label study with no control group. Considering the very high rates of virological response and the very good safety 
profile that had been previously demonstrated with DAA, the use of a control group would have been unethical in a population with a severe life-threatening disease. Some patients were treated for 12 weeks and others for 24 weeks, as the duration of antiviral therapy was individually tailored. The use of non-antiviral treatment, i.e. corticosteroids, immunosuppressants or plasmapheresis, was at the investigators’ discretion, although their use was fairly well distributed amongst the DAA groups.

In conclusion, the VASCUVALDIC 3 study demonstrates that in a large cohort of HCVCryoVas patients with long-term follow-up, different combinations of all oral, interferon- and ribavirin-free, sofosbuvir-based antiviral therapy are able to induce a high rate of clinical improvement at week 12 post-DAA treatment and at the end of follow-up. The tolerance was good, with no serious adverse events and a very low rate of DAA withdrawal due to side effects. It is noteworthy that the mortality rate was very low compared to previous studies. Less than $15 \%$ of patients required the use of corticosteroids or immunosuppressants combined with antiviral therapy. Of note, a longer follow-up of HCV-CryoVas patients with viral eradication and persistent detectable cryoglobulinemia is mandatory for evaluating the remaining risk of lymphoma. 


\section{Acknowledgments}

We would like to thank all the patients and their families. 


\section{References}

1. Ramos-Casals M, Stone JH, Cid MC, et al. The cryoglobulinaemias. Lancet. 2012;379:348360.

2. Meltzer M, Franklin EC, Elias K, et al. Cryoglobulinemia--a clinical and laboratory study. II. Cryoglobulins with rheumatoid factor activity. Am J Med. 1966;40:837-856.

3. Cacoub P, Comarmond C, Domont F, et al. Cryoglobulinemia Vasculitis. Am J Med. 2015;128:950-5.

4. Cacoub P, Poynard T, Ghillani P, et al. Extrahepatic manifestations of chronic hepatitis C. MULTIVIRC Group. Multidepartment Virus C. Arthritis Rheum. 1999;42:2204-2212.

5. Damoiseaux J, Cohen Tervaert JW. Diagnostics and Treatment of Cryoglobulinaemia: It Takes Two to Tango. Clin Rev Allergy Immunol. 2014;47:299-310.

6. Kondili LA, Vella S, Zignego AL; PITER collaborating Group. Mixed cryoglobulinaemia: An important but frequently unrecognized and underestimated HCV-related condition in the real life practice. Liver Int. 2017 Jun 9. [Epub ahead of print]

7. Ferri C, Sebastiani M, Giuggioli D, et al. Mixed cryoglobulinemia: demographic, clinical, and serologic features and survival in 231 patients. Semin Arthritis Rheum. 2004;33:355-374.

8. Terrier B, Cacoub P. Cryoglobulinemia vasculitis: an update. Curr Opin Rheumatol. 2013 Jan;25(1):10-8.

9. Fabrizi F, Plaisier E, Saadoun D, et al. Hepatitis C virus infection, mixed cryoglobulinemia, and kidney disease. Am J Kidney Dis. 2013 Apr;61(4):623-37.

10. Terrier B, Saadoun D, Sène D, et al. Presentation and outcome of gastrointestinal involvement in hepatitis $\mathrm{C}$ virus-related systemic vasculitis: a case-control study from a single-centre cohort of 163 patients. Gut. 2010 Dec;59(12):1709-15.

11. Terrier B, Cacoub P. Renal involvement in HCV-related vasculitis. Clin Res Hepatol Gastroenterol. 2013 Sep;37(4):334-9.

12. Terrier B, Karras A, Cluzel P, et al. Presentation and prognosis of cardiac involvement in hepatitis C virus-related vasculitis. Am J Cardiol. 2013 Jan 15;111(2):265-72.

13. Saadoun D, Rosenzwajg M, Joly F, et al. Regulatory T-cell responses to low-dose interleukin2 in HCV-induced vasculitis. N Engl J Med. 2011;365:2067-2077.

14. Ferri C, Cacoub P, Mazzaro C, et al. Treatment with rituximab in patients with mixed cryoglobulinemia syndrome: results of multicenter cohort study and review of the literature. Autoimmun Rev. 2011;11:48-55. 
15. Dammacco F, Sansonno D. Therapy for hepatitis C virus-related cryoglobulinemic vasculitis. N Engl J Med. 2013;369:1035-1045.

16. De Vita S, Quartuccio L, Isola M, et al. A randomized controlled trial of rituximab for the treatment of severe cryoglobulinemic vasculitis. Arthritis Rheum. 2012;64:843-853.

17. Sneller MC, Hu Z, Langford CA. A randomized controlled trial of rituximab following failure of antiviral therapy for hepatitis $C$ virus-associated cryoglobulinemic vasculitis. Arthritis Rheum. 2012;64:835-842.

18. Dammacco F, Tucci FA, Lauletta G, et al. Pegylated interferon-alpha, ribavirin, and rituximab combined therapy of hepatitis $\mathrm{C}$ virus-related mixed cryoglobulinemia: a long-term study. Blood. 2010;116:343-353.

19. Saadoun D, Resche Rigon M, Sene D, et al. Rituximab plus Peg-interferon-alpha/ribavirin compared with Peg-interferon-alpha/ribavirin in hepatitis C-related mixed cryoglobulinemia. Blood. 2010;116:326-334.

20. Saadoun D, Resche-Rigon M, Thibault V, et al. Antiviral therapy for hepatitis C virus-associated mixed cryoglobulinemia vasculitis: a long-term followup study. Arthritis Rheum. 2006;54:3696-3706

21. Gota C, Calabrese L. Induction of clinical autoimmune disease by therapeutic interferonalpha. Autoimmunity. 2003;36:511-518.

22. Boonyapisit K, Katirji B. Severe exacerbation of hepatitis C-associated vasculitic neuropathy following treatment with interferon alpha: a case report and literature review. Muscle Nerve. 2002;25:909-913.

23. Saadoun D, Resche Rigon M, Pol S, et al. PegIFNalpha/ribavirin/protease inhibitor combination in severe hepatitis $\mathrm{C}$ virus-associated mixed cryoglobulinemia vasculitis. $\mathrm{J}$ Hepatol. 2015;62:24-30.

24. Gragnani L, Fabbrizzi A, Triboli E, t al. Triple antiviral therapy in hepatitis C virus infection with or without mixed cryoglobulinaemia: a prospective, controlled pilot study. Dig Liver Dis. 2014;46:833-837.

25. Saadoun D, Thibault V, Si Ahmed SN, et al. Sofosbuvir plus ribavirin for hepatitis C virusassociated cryoglobulinaemia vasculitis: VASCUVALDIC study. Ann Rheum Dis. 2016;75:1777-82.

26. Sise ME, Bloom AK, Wisocky J, et al. Treatment of Hepatitis C Virus-Associated Mixed Cryoglobulinemia with Sofosbuvir-Based Direct-Acting Antiviral Agents. Hepatology. 2016;63:408-17.

27. Gragnani L, Visentini M, Fognani E, et al. Prospective study of guideline-tailored therapy with direct-acting antivirals for hepatitis $\mathrm{C}$ virus-associated mixed cryoglobulinemia. Hepatology. 2016;64:1473-82. 
28. Bonacci M, Lens S, Londoño MC, et al . Virologic, Clinical, and Immune Response Outcomes of Patients With Hepatitis C Virus-Associated Cryoglobulinemia Treated With Direct-Acting Antivirals. Clin Gastroenterol Hepatol. 2017 Apr;15(4):575-583

29. Saadoun D, Pol S, Ferfar Y, et al. Efficacy and Safety of Sofosbuvir Plus Daclatasvir for Treatment of HCV-Associated Cryoglobulinemia Vasculitis. Gastroenterology. 2017 Jul;153(1):49-52.

30. Harris NL, Jaffe ES, Diebold J, et al. World Health Organization classification of neoplastic diseases of the hematopoietic and lymphoid tissues: report of the Clinical Advisory Committee meeting-Airlie House, Virginia, November 1997. J Clin Oncol. 1999;17:38353849.

31. Laperche S, Saune K, Deny P, et al. Unique NS5b hepatitis C virus gene sequence consensus database is essential for standardization of genotype determinations in multicenter epidemiological studies. J Clin Microbiol. 2006;44:614-616.

32. Musset L, Diemert MC, Taibi F, et al. Characterization of cryoglobulins by immunoblotting. Clin Chem. 1992;38:798-802.

33. Brouet JC, Clauvel JP, Danon F, et al. Biologic and clinical significance of cryoglobulins. A report of 86 cases. Am J Med. 1974;57:775-788.

34. Intraobserver and interobserver variations in liver biopsy interpretation in patients with chronic hepatitis C. The French METAVIR Cooperative Study Group. Hepatology. 1994;20:15-20.

35. Monti G, Pioltelli P, Saccardo F, et al. Incidence and characteristics of non-Hodgkin lymphomas in a multicenter case file of patients with hepatitis $C$ virus-related symptomatic mixed cryoglobulinemias. Arch Intern Med. 2005;165:101-105.

36. Comarmond C, Garrido M, Pol S, et al. Direct-Acting Antiviral Therapy Restores Immune Tolerance to Patients With Hepatitis C Virus-Induced Cryoglobulinemia Vasculitis. Gastroenterology. 2017 Jun;152 (8):2052-2062

37. Sollima S, Milazzo L, Peri AM, et al. Persistent mixed cryoglobulinaemia vasculitis despite hepatitis $\mathrm{C}$ virus eradication after interferon-free antiviral therapy. Rheumatol. (United Kingdom) 2016;55:2084-2085.

38. Sise ME, Wisocky J, Rosales IA, et al. Lupus-Like Immune Complex-Mediated Glomerulonephritis in Patients With Hepatitis C Virus Infection Treated With Oral, Interferon-Free, Direct-Acting Antiviral Therapy. Kidney Int. Reports 2016;1:135-143.

39. Santer DM, Ma MM, Hockman D, et al. Enhanced Activation of Memory, but Not Naïve, B Cells in Chronic Hepatitis C Virus-Infected Patients with Cryoglobulinemia and Advanced Liver Fibrosis. PLoS One 2013;8. 
40. Vallat L, Benhamou Y, Gutierrez M, et al. Clonal B cell populations in the blood and liver of patients with chronic hepatitis C virus infection. Arthritis Rheum. 2004 Nov;50(11):3668-78

41. Saadoun D, Sellam J, Ghillani-Dalbin P, et al. Increased risks of lymphoma and death among patients with non-hepatitis C virus-related mixed cryoglobulinemia. Arch Intern Med. 2006;166:2101-2108.

42. Landau DA, Saadoun D, Halfon P, et al. Relapse of hepatitis C virus-associated mixed cryoglobulinemia vasculitis in patients with sustained viral response. Arthritis Rheum. 2008;58:604-611. 


\section{Legends of tables and figures}

Table 1: Main baseline features of 148 patients with HCV-associated mixed cryoglobulinemia vasculitis.

Table 2: Main baseline features of patients with HCV-associated mixed cryoglobulinemia vasculitis according to the response of vasculitis manifestations after interferon-free direct-acting antiviral agents.

Table 3: Main features of patients with HCV-associated mixed cryoglobulinemia vasculitis according to the combination of interferon-free direct-acting antivirals.

Figure 1: Complete clinical response of $\mathrm{HCV}$-associated cryoglobulinemia vasculitis according to different direct-acting antivirals (DAA) after adjustment for severity of the vasculitis and type of mixed cryoglobulin. 
Table 1: Main baseline features of 148 patients with HCV-associated mixed cryoglobulinemia vasculitis.

\begin{tabular}{|c|c|c|}
\hline Characteristics & Number or mean & Percentage \\
\hline Age, yrs & $57[51 ; 67]$ & - \\
\hline Gender F/M & $73 / 58$ & $55.7-44.3$ \\
\hline \multicolumn{3}{|l|}{ HCV infection } \\
\hline \multicolumn{3}{|l|}{ HCV genotype } \\
\hline 1 & 79 & 53.4 \\
\hline 2 & 19 & 12.8 \\
\hline 3 & 16 & 10.8 \\
\hline 4 & 28 & 18.9 \\
\hline 5 & 5 & 3.4 \\
\hline 6 & 1 & 0.7 \\
\hline \multicolumn{3}{|l|}{ Liver fibrosis (METAVIR) } \\
\hline F0-F2 & 59 & 46.3 \\
\hline F3-F4 & 70 & 53.7 \\
\hline HCV RNA, log IU/mL & $6.04[5.3 ; 6.5]$ & - \\
\hline$A L T, I U / L$ & $45[24 ; 77]$ & - \\
\hline Serum albumin, $\mathrm{g} / \mathrm{L}$ & $39[35 ; 42]$ & - \\
\hline \multicolumn{3}{|l|}{ Previous IFN-based treatments } \\
\hline Naïve & 73 & 49.3 \\
\hline Non-responder & 75 & 50.7 \\
\hline \multicolumn{3}{|l|}{ Mixed cryoglobulinemia-related } \\
\hline Cryoglobulinemia positive & 132 & 90.4 \\
\hline Cryoglobulinemia type II & 87 & 70.7 \\
\hline Cryoglobulinemia type III & 36 & 29.3 \\
\hline Cryoglobulinemia level, mg/L & $168[50 ; 447]$ & - \\
\hline Low C4 serum level & 61 & 70.1 \\
\hline Serum creatinine, $\mu \mathrm{mol} / \mathrm{L}$ & $70[60 ; 84]$ & - \\
\hline Glomerular filtration rate, $\mathrm{mL} / \mathrm{min}$ & $90[67 ; 111]$ & - \\
\hline \multicolumn{3}{|l|}{ Vasculitis } \\
\hline Arthralgia & 94 & 64.4 \\
\hline Purpura & 85 & 57.4 \\
\hline Skin necrosis & 15 & 10.1 \\
\hline Neuropathy & 86 & 58.1 \\
\hline Renal involvement & 25 & 16.9 \\
\hline Hypertension & 44 & 29.7 \\
\hline Severe form of vasculitis* & 43 & 29.1 \\
\hline B-cell lymphoma & 13 & 8.8 \\
\hline \multicolumn{3}{|l|}{ Previous immunosuppressant } \\
\hline Corticosteroids & 25 & 18.4 \\
\hline Rituximab & 3 & 2.2 \\
\hline Plasma exchange & 5 & 3.7 \\
\hline \multicolumn{3}{|l|}{ Corticosteroids, rituximab or plasma } \\
\hline exchange & 29 & 21.3 \\
\hline
\end{tabular}

HCV: hepatitis C virus; ALT: alanine aminotransferase; IFN: interferon alfa. Data are expressed as $\mathrm{n}$ (\%) or mean \pm SEM. * with skin necrosis, glomerulonephritis, and involvement of central nervous system, heart or gut. 
Table 2: Main baseline features of patients with $\mathrm{HCV}$-associated mixed cryoglobulinemia vasculitis according to the response of vasculitis manifestations after interferon-free direct-acting antiviral treatment.

\begin{tabular}{|c|c|c|c|c|c|}
\hline Characteristics & \multicolumn{2}{|c|}{$\begin{array}{l}\text { Partial or non-response } \\
\text { Number/mean }\end{array}$} & \multicolumn{2}{|c|}{$\begin{array}{l}\text { Complete response } \\
\text { Number/mean }\end{array}$} & $\begin{array}{c}\mathrm{p}- \\
\text { value }\end{array}$ \\
\hline Total number & 40 patients & 27.4 & 106 patients & 72.6 & \\
\hline Age & $63[54 ; 68]$ & - & $57[51 ; 66]$ & - & 0.22 \\
\hline Female gender & 16 & 61.5 & 55 & 53.4 & 0.51 \\
\hline \multicolumn{6}{|l|}{ HCV infection } \\
\hline FO-F2 & 13 & 52 & 45 & 44.1 & 0.51 \\
\hline F3-F4 & 13 & 50 & 57 & 55.9 & 0.56 \\
\hline HCV RNA, log IU/mL & $5.84[5.1 ; 6.3]$ & - & $6.08[5.36 ; 6.50]$ & - & 0.40 \\
\hline ALT, IU/L & $41[25 ; 66]$ & - & $47[24 ; 79]$ & - & 0.69 \\
\hline Serum albumin, $\mathrm{g} / \mathrm{L}$ & $36[31 ; 40]$ & - & $40[35 ; 43]$ & - & 0.048 \\
\hline \multicolumn{6}{|l|}{ Previous IFN-based treatments } \\
\hline Naïve & 12 & 40 & 59 & 50.9 & 0.31 \\
\hline Non-responder & 18 & 60 & 57 & 49.1 & 0.31 \\
\hline \multicolumn{6}{|l|}{ Mixed cryoglobulinemia-related } \\
\hline Cryoglobulinemia positive & 28 & 93.3 & 103 & 90.4 & 1.00 \\
\hline Cryoglobulinemia type II & 19 & 73.1 & 67 & 62 & 0.62 \\
\hline Cryoglobulinemia type III & 5 & 19.2 & 31 & 28.7 & 0.62 \\
\hline Cryoglobulinemia level, mg/L & $80[44.5 ; 377]$ & - & $196[72 ; 577]$ & - & 0.23 \\
\hline Low C4 serum level & 13 & 72.2 & 47 & 70.2 & 1.00 \\
\hline Serum creatinine, $\mu \mathrm{mol} / \mathrm{L}$ & $70[60 ; 103]$ & - & $69[61 ; 82]$ & - & 0.67 \\
\hline $\begin{array}{l}\text { Glomerular filtration rate, } \mathrm{mL} / \mathrm{min} \\
\text { Vasculitis }\end{array}$ & $87[46 ; 113]$ & - & $90[71 ; 111]$ & - & 0.37 \\
\hline Arthralgia & 20 & 66.7 & 73 & 64 & 0.83 \\
\hline Purpura & 19 & 63.3 & 65 & 56 & 0.54 \\
\hline Skin necrosis & 3 & 10 & 11 & 9.5 & 1.00 \\
\hline Neuropathy & 22 & 73.3 & 63 & 54.3 & 0.065 \\
\hline Renal involvement & 9 & 30 & 15 & 12.2 & 0.049 \\
\hline Hypertension & 14 & 46.7 & 29 & 25 & 0.026 \\
\hline Severe form of vasculitis* & 14 & 35 & 28 & 26 & 0.31 \\
\hline B-cell lymphoma & 1 & 3.3 & 12 & 10.3 & 0.30 \\
\hline \multicolumn{6}{|l|}{ Previous immunosuppressant } \\
\hline Corticosteroids & 9 & 34.6 & 15 & 13.9 & 0.021 \\
\hline Rituximab & 1 & 3.9 & 2 & 1.9 & 0.48 \\
\hline Plasma exchange & 0 & 0 & 5 & 4.6 & 0.58 \\
\hline $\begin{array}{l}\text { Corticosteroids, rituximab or plasma } \\
\text { exchange }\end{array}$ & 9 & 34.6 & 19 & 17.6 & 0.065 \\
\hline
\end{tabular}

HCV: hepatitis C virus; ALT: alanine aminotransferase; IFN: interferon alfa. Data are expressed as $\mathrm{n}$ (\%) or mean \pm SEM. * with skin necrosis, glomerulonephritis, and involvement of central nervous system, heart or gut. 
Table 3: Main features of patients with HCV-associated mixed cryoglobulinemia vasculitis according to the combination of interferon-free direct-acting antivirals.

\begin{tabular}{|c|c|c|c|c|c|c|c|c|c|}
\hline \multirow[t]{2}{*}{ DAA combination } & & SOF/LEDI & & SOF/DACLA & & SOF/SIME & & SOF/RIBA & \multirow[b]{3}{*}{ p-value } \\
\hline & & Median [IQR] & & Median [IQR] & & Median [IQR] or & & Median & \\
\hline Characteristics & $\mathbf{N}$ & or $\%$ & $\mathbf{N}$ & or $\%$ & $\mathbf{N}$ & $\%$ & $\mathbf{N}$ & [IQR] or \% & \\
\hline Total number & 23 & & 53 & & 18 & & 51 & & \\
\hline Age, years & & $57[51 ; 66]$ & & $57[51 ; 64]$ & & $62[53 ; 69]$ & & $60[54 ; 68]$ & 0.35 \\
\hline Weight, kg & & $70[65 ; 81]$ & & $71[59 ; 86]$ & & $71[55 ; 84]$ & & $70[60 ; 80]$ & 0.93 \\
\hline Female gender, n, \% & 14 & $64 \%$ & 21 & $48 \%$ & 10 & $67 \%$ & 28 & $58 \%$ & 0.50 \\
\hline HCV genotype 3, 5 or 6 & 1 & $4 \%$ & 14 & $26 \%$ & 0 & $0 \%$ & 7 & $14 \%$ & 0.014 \\
\hline \multicolumn{10}{|l|}{ Liver fibrosis (METAVIR) } \\
\hline F0-F2 & 15 & $65 \%$ & 19 & $42 \%$ & 4 & $25 \%$ & 19 & $46 \%$ & 0.094 \\
\hline F3-F4 & 8 & $35 \%$ & 26 & $58 \%$ & 12 & $75 \%$ & 23 & $55 \%$ & 0.095 \\
\hline HCV RNA, log IU/mL & & $6.1[5.9 ; 6.3]$ & & $6.2[5.5 ; 6.6]$ & & $5.8[5.4 ; 6.3]$ & & $5.7[5.1 ; 6.3]$ & 0.059 \\
\hline ALT, IU/L & & $43[26 ; 73]$ & & $41[23 ; 79]$ & & $59[39 ; 79]$ & & $47[25 ; 79]$ & 0.78 \\
\hline Serum albumin, $\mathrm{g} / \mathrm{L}$ & & $41[39 ; 43]$ & & $37[32 ; 40]$ & & $40[35 ; 43]$ & & $38[34 ; 41]$ & 0.069 \\
\hline \multicolumn{10}{|l|}{ Mixed cryoglobulinemia-related } \\
\hline Cryoglobulinemia positive & 22 & $100 \%$ & 46 & $88 \%$ & 15 & $83 \%$ & 46 & $90 \%$ & 0.28 \\
\hline Cryoglobulinemia type II & 9 & $50 \%$ & 31 & $65 \%$ & 10 & $63 \%$ & 35 & $69 \%$ & 0.31 \\
\hline Cryoglobulinemia type III & 9 & $50 \%$ & 11 & $23 \%$ & 4 & $25 \%$ & 11 & $22 \%$ & 0.31 \\
\hline Cryoglobulinemia level, mg/L & & $126[90 ; 248]$ & & $190[44 ; 552]$ & & $241[19 ; 730]$ & & $115[50 ; 372]$ & 0.95 \\
\hline Low C4 serum level & 2 & $40 \%$ & 24 & $71 \%$ & 5 & $56 \%$ & 30 & $79 \%$ & 0.19 \\
\hline Serum creatinine, $\mu \mathrm{mol} / \mathrm{L}$ & & $69[58 ; 82]$ & & $69[60 ; 79]$ & & $75[63 ; 86]$ & & $70[62 ; 91]$ & 0.73 \\
\hline Glomerular filtration rate, $\mathrm{mL} / \mathrm{min}$ & & $92[79 ; 111]$ & & $95[72 ; 116]$ & & $85[59 ; 94]$ & & $88[64 ; 109]$ & 0.32 \\
\hline \multicolumn{10}{|l|}{ Vasculitis } \\
\hline Arthralgia & 14 & $61 \%$ & 33 & $62 \%$ & 13 & $72 \%$ & 31 & $61 \%$ & 0.85 \\
\hline Purpura & 5 & $22 \%$ & 30 & $57 \%$ & 9 & $50 \%$ & 39 & $76 \%$ & 0.0001 \\
\hline
\end{tabular}




\begin{tabular}{|c|c|c|c|c|c|c|c|c|c|}
\hline Skin necrosis & 1 & $4 \%$ & 7 & $13 \%$ & 1 & $6 \%$ & 5 & $10 \%$ & 0.73 \\
\hline Neuropathy & 12 & $52 \%$ & 28 & $53 \%$ & 9 & $50 \%$ & 36 & $71 \%$ & 0.19 \\
\hline Renal involvement & 4 & $17 \%$ & 8 & $15 \%$ & 3 & $17 \%$ & 10 & $20 \%$ & 0.96 \\
\hline Hypertension & 6 & $26 \%$ & 13 & $25 \%$ & 5 & $28 \%$ & 20 & $39 \%$ & 0.40 \\
\hline Severe form of vasculitis & 6 & $26 \%$ & 17 & $32 \%$ & 4 & $22 \%$ & 15 & $29 \%$ & 0.89 \\
\hline B-cell lymphoma & 0 & $0 \%$ & 1 & $2 \%$ & 2 & $11 \%$ & 10 & $20 \%$ & 0.005 \\
\hline \multicolumn{10}{|l|}{ Non-antiviral treatments } \\
\hline Erythropoietin & 0 & $0 \%$ & 7 & $13 \%$ & 0 & $0 \%$ & 16 & $37 \%$ & 0.0001 \\
\hline Corticosteroids & 1 & $5 \%$ & 13 & $25 \%$ & 4 & $27 \%$ & 7 & $16 \%$ & 0.16 \\
\hline Rituximab & 0 & $0 \%$ & 1 & $2 \%$ & 2 & $13 \%$ & 0 & $0 \%$ & 0.047 \\
\hline Plasma exchange & 0 & $0 \%$ & 2 & $4 \%$ & 0 & $0 \%$ & 3 & $7 \%$ & 0.66 \\
\hline Corticosteroids, rituximab or PE & 1 & $5 \%$ & 14 & $26 \%$ & 4 & $27 \%$ & 10 & $23 \%$ & 0.15 \\
\hline \multicolumn{10}{|l|}{ Side effects } \\
\hline Anemia & 0 & $0 \%$ & 5 & $10 \%$ & 3 & $19 \%$ & 11 & $29 \%$ & 0.007 \\
\hline Infection & 0 & $0 \%$ & 0 & $0 \%$ & 0 & $0 \%$ & 2 & $5 \%$ & 0.25 \\
\hline Nausea & 0 & $0 \%$ & 1 & $2 \%$ & 1 & $6 \%$ & 0 & $0 \%$ & 0.46 \\
\hline
\end{tabular}

DAA: direct-acting antivirals; SOF: sofosbuvir; LEDI: ledipasvir; DACLA: daclatasvir; SIME: simeprevir; RIBA: ribavirin; severe form of vasculitis, i.e. with skin necrosis, glomerulonephritis, and involvement of kidney, central nervous system, heart or gut. PE= plasma exchange; NA=not available. Data are expressed as $n(\%)$ or mean \pm SEM. 